\title{
Frosch im Mund
}

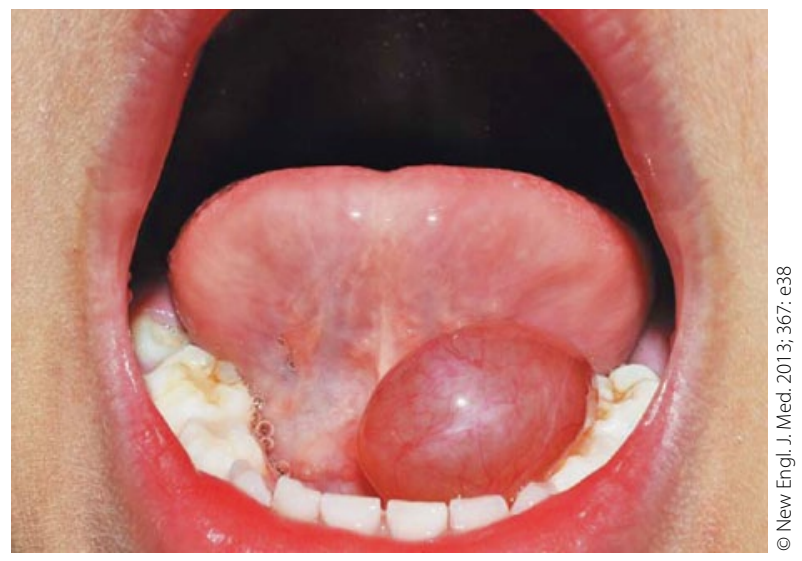

Raumforderung unter der Zunge bei einem sechsjährigen Mädchen.

- Bei einem gesunden sechsjährigen Mädchen fiel seit einigen Wochen eine kugelige Schwellung unter der Zunge auf. Kongenitale Fehlbildungen bestanden nicht, auch ein Trauma war nicht bekannt.

Bei einem Durchmesser der Läsion von $3 \mathrm{~cm}$ klagte das Mädchen über Probleme beim Schlucken und Sprechen. Die Raumforderung ging von der linken Hälfte des Mundbodens aus und fluktuierte leicht, war aber nicht druckdolent. Die darüber liegende Schleimhaut zeigte keine Auffälligkeiten. Unter der klinischen Diagnose einer Ranula wurde die Läsion in Vollnarkose exzidiert.

\section{Kommentar}

Die Ranula (lat. für Fröschlein) ist eine Retentionszyste der sublingualen Speicheldrüsen, die durch eine Ruptur oder eine Verstopfung des Ausführungsgangs der Glandulae sublinguales hervorgerufen wird. Ursache ist wahrscheinlich eine dysgenetische Differenzierungsstörung des Gangsystems. Nimmt die Ranula an Größe zu, kann es unter Umständen zu Schluck-, Sprech- und Atembeschwerden kommen. Zu den Differenzialdiagnosen der Vorwölbungen in diesem Bereich gehören Gefäßmalformationen wie Lymphangiome, Abszesse oder Weichteiltumoren. Im vorliegenden Fall bestätigte sich histologisch der Verdacht einer Speicheldrüsenzyste oder Retentionszyste in der Art einer Ranula. Zu einem Rezidiv kam es im Lauf des Jahres nach der Exzision nicht.

- A. Hernandez-Martin und A. Torrelo (Korres.: ahernandez_hnj@yahoo.es): Ranula. New Engl. J. Med. 2013; 367: e38 